7 - ORIGINAL ARTICLE EXPERIMENTAL UROLOGY

\title{
Characterization of an experimental model of progressive renal disease in rats ${ }^{1}$
}

\author{
Nilo César do Vale BarachoI, Lucas Miranda Kangussu" ${ }^{I I}$, Thiago Ruiz Rodrigues Prestes ${ }^{\text {III }}$, Kátia Daniela da Silveira ${ }^{I V}$, Regina \\ Maria Pereirav ${ }^{\text {, Natália Pessoa Rochavi, Ana Cristina Simões e Silva }}{ }^{\text {VII }}$
}

DOI: http://dx.doi.org/10.1590/S0102-865020160110000007

IFull Professor, Departament of Biochemistry and Pharmacology, School of Medicine, Itajuba-MG, Brasil. Conception and design of the study; acquisition, analysis and interpretation of data; technical procedures; histopathological examinations; manuscript preparation and writing, final approval.

IIPhD, Interdisciplinary Laboratory of Medical Research, School of Medicine, Universidade Federal de Minas Gerais (UFMG), Belo Horizonte-MG, Brasil. Analysis and interpretation of data, statistical analysis, manuscript writing, final approval.

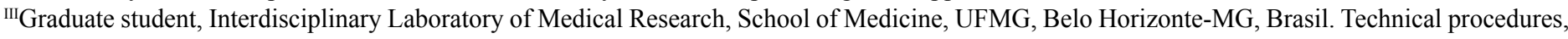
manuscript preparation, final approval.

${ }^{\mathrm{IV}} \mathrm{PhD}$, Interdisciplinary Laboratory of Medical Research, School of Medicine, UFMG, Belo Horizonte-MG, Brasil. Conception and design of the study, acquisition of data, technical procedures, histopathological examinations, manuscript preparation, final approval.

vPhD, Fundação Hospitalar do Estado de Minas Gerais, Belo Horizonte-MG, Brasil. Conception and design of the study, acquisition of data, technical procedures, manuscript preparation, final approval.

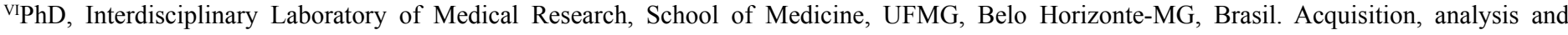
interpretation of data, manuscript preparation, critical revision, final approval.

${ }^{\mathrm{VII}}$ Full Professor, Interdisciplinary Laboratory of Medical Research, School of Medicine, UFMG, Belo Horizonte-MG, Brasil. Conception and design of the study, interpretation of data, statistical analysis, histopathological examinations, manuscript preparation and writing, critical revision, final approval.

\footnotetext{
ABSTRACT

PURPOSE: To characterize an experimental model of progressive renal disease induced by different degrees of nephrectomy in rats.

METHODS: Eighty male Wistar rats were divided into four experimental groups (n=20/group): sham surgery (control group), progressive degrees of nephrectomy leading to mild uremia (group 1), moderate uremia (group 2) and severe uremia (group 3). Ten animals of each group were followed for two or four weeks. At the end, blood and 24-hour urine samples were collected to determine renal function parameters. Urine output and water and food intake were daily monitored.

RESULTS: In rats of group 1, serum levels of creatinine and urea and microalbuminuria were increased, while reduced creatinine clearance ( $p<0.05$, compared with control group), without changing blood pressure. Animals of group 2 had more accentuated alterations: increases in urinary output, blood pressure, serum concentrations of urea, creatinine, sodium, potassium, and in microalbuminuria, and reduction of creatinine clearance $(\mathrm{p}<0.05)$. Group 3 exhibited even more increased serum concentrations of urea, creatinine, sodium and potassium, blood pressure and microalbuminuria, and decreased creatinine clearance $(\mathrm{p}<0.05)$ in comparison with control group and unilateral nephrectomy.
}

CONCLUSION: Progressive nephrectomy in rats seems to be useful to study the physiopathology of chronic kidney disease and its mechanisms of progression.

Key words: Renal Insufficiency, Chronic. Nephrectomy. Models, Animal. Rats. 


\section{Introduction}

Chronic kidney disease (CKD) is defined as a clinical syndrome characterized by progressive loss of renal function, with decline of the glomerular filtration rate and increase of nitrogen metabolites, caused by evolving and irreversible morphological changes in the renal parenchyma ${ }^{1}$. The worldwide incidence of CKD has been increasing exponentially, especially because of the high global prevalence of the main causes of CKD, including diabetes mellitus, hypertension, and obesity ${ }^{1-3}$. It is estimated that about 50.000 deaths occur annually in the United States as result of renal insufficiency, with an annual incidence of end-stage renal disease (ESRD) of 336 per million inhabitants, while in European countries the average is 135 per million ${ }^{4}$.

Clinical and epidemiological evidence show an association of multiple factors responsible for the onset and progression of $\mathrm{CKD}^{5}$. The progression of the disease is variable, depending on the risk factors involved in this process ${ }^{5}$. Hypertension is considered one of the most important risk factors for both CDK onset and progression ${ }^{5,6}$. Besides that, types 1 and 2 diabetes mellitus, especially if poorly controlled, accelerates the progression of diabetic nephropathy, leading to ESRD ${ }^{1}$. There are also the non-variable risk factors of CKD, including genetic alterations, race, age, and sex. Therefore, the progression of CKD is greater in elderly, male, and black patients. It is believed that, as result of initial loss of nephron number, remnant nephrons have to compensate with hyperfiltration and suffer hypertrophy, changes in glomerular surface, and increase in glomerular basement membrane permeability to proteins ${ }^{4}$. Thereby, proteinuria is a strong marker of CKD severity and an independent predictor of progression to $\mathrm{ESRD}^{7}$.

Experimental models of CKD are obtained by administration of drugs such as gentamicin, cyclosporine ${ }^{8}$, and adenosine ${ }^{9}$, or by surgical removal of renal tissue ${ }^{10}$. This last model was originally described by Ormrod and Miller in $1980^{11}$, when the authors showed that surgical removal of a significant portion of the rat kidneys causes adaptive changes in remnant nephrons capable of leading to increase of glomerular filtration rate and urinary output. The subtotal nephrectomy model, which consists of unilateral nephrectomy associated to the removal of $5 / 6$ of the remaining kidney, has been widely used as model of ESRD, defined as when the animal has $10 \%$ or less of its kidney function ${ }^{11-15}$. However, studies that followed the original description of Ormrod and Miller have not characterized the parameters of renal function and the histological changes resulting from CKD in this experimental of model of nephrectomy in different levels. Thereby, the objective of this study was to characterize the progression of CKD induced by progressive levels of nephrectomy leading to leading to mild, moderate and severe uremia in rats with regard to morphological and functional changes.

\section{Methods}

The study was in accordance with Brazilian Federal Law on Animal Experimentation (Law 11794/08) and guidelines of the Brazilian College of Animal Experimentation and was approved by the Research Ethics Committee of Faculdade de Medicina de Itajubá under the protocol number PAN 23/2007.

Eighty male Wistar rats (60-90 days of age) weighing 200-250g were obtained from the animal facility of Faculdade de Medicina de Itajubá. Animals were housed in metabolic cages under a 12-hour light/dark cycle and had ad libitum access to water and standard chow.

The animals were anethesized with ketamine $(50 \mathrm{mg} /$ $\mathrm{kg})$ and xylazine $(25 \mathrm{mg} / \mathrm{kg})$ intraperitoneally and submitted to progressive levels of nephrectomy in order to induce three different stages of CKD, based on serum urea concentration: mild, moderate and severe. We have reproduced the technique originally proposed by Ormond and Miller ${ }^{11}$, which classified the progressive degrees of nephrectomy based on the alteration produced on plasma levels of urea as mild, moderate and severe. Figure 1 is a schematic view of the surgical procedures adopted to induce mild uremia (group 1), moderate uremia (group 2) and severe uremia (group 3).

\section{Mild uremia (Group 1)}

Following trichotomy and aseptic disinfection, a left flank incision was made, the left kidney was exposed and had its capsule and adhering fat dissected. The adrenal gland was preserved and the incision was sutured. After seven days, the right kidney was exposed under the same technique. The right kidney had its pedicle ligated and was removed (Figure 1A).

\section{Moderate uremia (Group 2)}

After exposition of the left kidney using the procedures described above, its superior and inferior poles were removed, as well as one third of the cortical tissue of its external lateral portion. After seven days, the right kidney had its pedicle ligated and was removed (Figure 1B).

\section{Severe uremia (Group 3)}

The procedures described above were again performed to expose the left kidney. Afterwards, the superior and inferior lobes 
and one third of the cortical tissue of the external lateral portion were removed, as well as $2 \mathrm{~mm}$ of the ventral and dorsal portions of the kidney. After seven days, the right kidney had its pedicle ligated and was removed. The procedure to induce severe uremia is shown in Figure 1C.

\section{Sham surgery - Control group}

The left kidney was surgically exposed and a small portion of its cortical tissue was removed. After seven days, the right kidney was exposed and manipulated (Figure 1D).

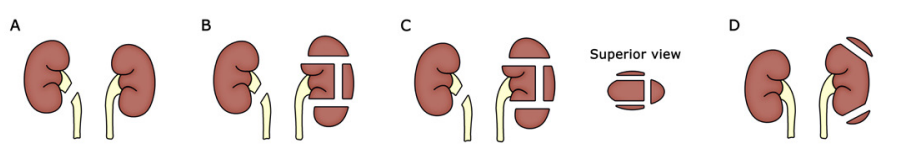

FIGURE 1- Schematic view of the surgical technique proposed by Ormond and Miller ${ }^{11}$ to induce mild uremia $(\mathbf{A})$, moderate uremia $(\mathbf{B})$ and severe uremia (C). Panel D represents sham-operated animals as control group. Panel A shows the exposition of the capsule of the left kidney and the dissection of the adhering fat tissue. After seven days, the pedicle of the right kidney is ligated and the right kidney is removed. Panel B shows the removal of superior and inferior poles of the left kidney, as well as one third of the cortical tissue of its external lateral portion. After seven days, the pedicle of the right kidney is ligated and the right kidney is removed. Panel $\mathbf{C}$ shows the removal of the superior and inferior lobes and one third of the cortical tissue of the external lateral portion, as well as $2 \mathrm{~mm}$ of the ventral and dorsal portions of the left kidney. After seven days, the pedicle of the right kidney is ligated and the right kidney is removed. Panel D represents sham surgery, in which the left kidney is surgically exposed to remove a small portion of its cortical tissue. After seven days, the right kidney is exposed and manipulated.

Following that, the animals were placed into metabolic cages (Tecniplast, USA) with water and standard chow ad libitum and were divided into four experimental groups $(n=20$ each group): 1- Sham surgery (control group); 2- Mild uremia (group 1); 3- Moderate uremia (group 2); 4- Severe uremia (group 3). Ten animals from each group were followed for two weeks and the other half $(n=10)$ for four weeks.

Mean arterial pressure (MAP) of all animals was measured weekly by tail plethysmography (Kent Scientific, Torrington, CT). Urine output, water and food intake were measured daily. Urine samples were collected daily, centrifuged at $2500 \mathrm{rpm}$ (Excelsa, FANEN) and stored at $-20^{\circ} \mathrm{C}$ for measurement of creatinine, microalbuminuria, $\mathrm{Na}^{+}$and $\mathrm{K}^{+}$.

At the end of the experimental period (two or four weeks), rats were anesthesized with ketamine $(50 \mathrm{mg} / \mathrm{kg})$ and xylazine $(25$ $\mathrm{mg} / \mathrm{kg}$ ) i.p. in order to collect blood samples by cardiac puncture. The samples were centrifuged at $2500 \mathrm{rpm}$ (Excelsa, FANEN) and the obtained serum was stored at $-20^{\circ} \mathrm{C}$ for dosage of creatinine, urea, $\mathrm{Na}^{+}$and $\mathrm{K}^{+}$.

\section{Determination of renal function parameters}

Serum and urine creatinine concentrations were determined using a modified Jaffe colorimetric method (LabTest, Minas Gerais, Brazil). Creatinine clearance was calculated using the following formula:

\section{Urine creatinine concentration $\mathrm{x}$ Urine volume}

Serum creatinine concentration $\mathrm{x}$ Urine collection time

Serum urea concentration was obtained by the urease enzymatic method (LabTest, Minas Gerais, Brazil), serum and urine $\mathrm{Na}^{+}$and $\mathrm{K}^{+}$concentrations were determined by flame photometry (CELM, Brazil) and microalbuminuria in 24-hour urine samples was measured by turbidimetry (Gold Analisa Diagnóstica, Minas Gerais, Brazil).

\section{Histopathological analysis}

The animals were euthanized and the kidneys were removed and cut into $2 \mathrm{~mm}$ slices, which were fixed for 24 hours in $10 \%$ buffered formalin. After fixation, the sections were embedded in paraffin, sliced into 5 micra slides and stained with hematoxylin and eosin. Afterwards, the histological slides were examamined under an optical microscope (Nikon Eclipse, Japan) and images of illustrative fields were obtained.

\section{Statistical analysis}

Results were expressed as the mean \pm standard deviation from the mean or median, when appropriate. Statistical analyses were performed using the software STASTITICA 5.0 (StatSoft Brasil). The Shapiro-Wilk normality test was used to assess whether the data followed a normal distribution. Analysis of variance (ANOVA) was used for comparisons between the groups that were normally distributed. The Kruskal-Wallis test followed by Dunn's post hoc test was used to compare nonparametric data. The significance level was set at $\mathrm{p}<0.05$.

\section{Results}

\section{Urine output}

Urine output of the animals of the control group, group 1, group 2 and group 3 is shown in Figure 2 for the two-week experimental period and in Figure 3 for the four-week experimental period. The group of animals with mild uremia did not present significant changes in urine output after two or four weeks of 
experiment, compared to the control group. On the other hand, the group with moderate uremia presented statistically significant increase in urine output from day 3 to the end of the two-week experimental period $(\mathrm{p}<0.05)$, with the exception of day 12 $(p>0.05)$, and from day 2 to the end of the four-week experimental group ( $\mathrm{p}<0.05$ ), compared to the control group. In the same way, animals with severe uremia had increased urine output from day 1 to day 11 in the two-week period $(\mathrm{p}<0.05)$ and from day 2 to the end of the four-week period $(p<0.05)$, compared to the control group.

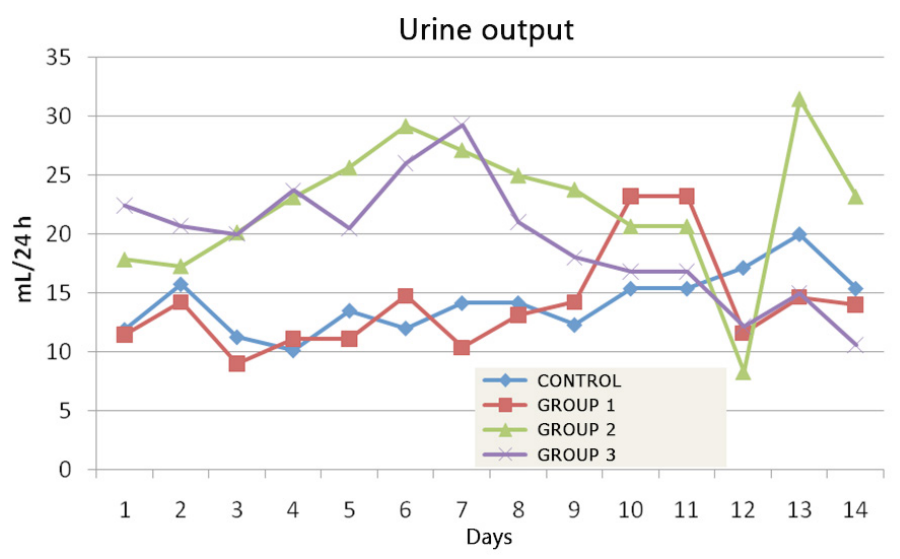

FIGURE 2 - Urinary output $(\mathrm{ml} / 24 \mathrm{~h})$ of sham-operated rats (control group) and of rats submitted to progressive degrees of nephrectomy leading to mild uremia (group 1), moderate uremia (group 2) and severe uremia (group 3), for two weeks after the experimental procedures.

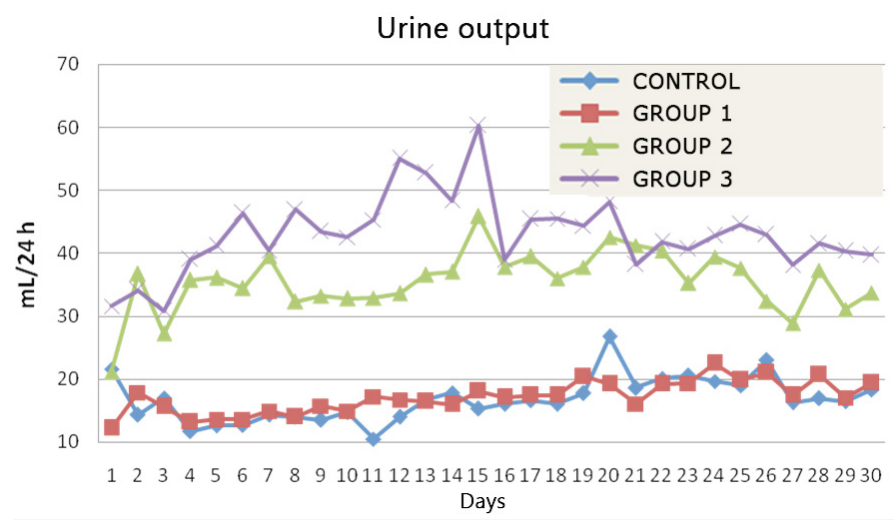

FIGURE 3 - Urinary output $(\mathrm{ml} / 24 \mathrm{~h})$ of sham-operated rats (control group) and of rats submitted to progressive degrees of nephrectomy leading to mild uremia (group 1), moderate uremia (group 2) and severe uremia (group 3), for four weeks after the experimental procedures.

\section{Food and water intake}

The different degrees of CKD produced in the studied groups did not result in changes in food intake of animals followed by two or four weeks, when compared to the control group $(p>0.05)$. Regarding water intake, significant changes were not observed in group 1, in both experimental periods, or in group
2 , in the two-week experimental period, when compared to the control group $(\mathrm{p}>0.05)$. However, animals with moderate uremia (group 2) presented increase in water intake on days 17, 19, 20, 21 and 24 in the four-week experimental period, compared to the control group $(\mathrm{p}<0.05)$, and on days $5,6,7,8,15,17,19,20$ and 21 , compared to rats with mild uremia $(\mathrm{p}<0.05)$

Similarly, the group of severe uremia (group 3) resulted in significant increase in water intake from day 1 to day 11 , in the two-week period $(\mathrm{p}<0.05)$, and from day 5 to the end of the experiment, except for days 6 and 16 ( $p>0.05)$, in the four-week period $(\mathrm{p}<0.05)$, compared to the control group.

\section{Renal function biochemical parameters}

The results regarding renal function biochemical parameters after two and four weeks are shown in Tables 1 and 2, respectively. Animals with mild uremia (group 1) presented significant increase in serum levels of creatinine and urea and presence of microalbuminuria $(\mathrm{p}<0.05)$, in both experimental periods, compared to the control group. In the same way, the animals of this experimental group presented a significant decrease of about $29 \%$ in creatinine clearance two weeks after surgery and of $35 \%$ four weeks after surgery, when compared to the control group $(\mathrm{p}<0.05)$.

TABLE 1 - Renal function parameters of the control group and of animals with mild (group 1), moderate (group 2 and severe uremia (group 2) induced by progressive removal of renal tissue according to the technique proposed by Ormond and Miller ${ }^{11}$.

\begin{tabular}{ccccc}
\hline \multicolumn{5}{c}{ Renal function parameters (at two weeks) } \\
Parameters & Control & Group 1 & Group 2 & Group 3 \\
\hline Serum $\mathrm{Na}^{+}(\mathrm{mEq} / \mathrm{l})$ & $141.3 \pm 2.3$ & $144.0 \pm 2.6$ & $155.8 \pm$ & $167.3^{ \pm}$ \\
& & & $2.0^{\mathrm{a}}$ & $2.8^{\mathrm{a}}$ \\
Serum $\mathrm{K}^{+}(\mathrm{mEq} / \mathrm{l})$ & $4.3 \pm 0.23$ & $4.7 \pm 0.5$ & $5.7 \pm 0.3^{\mathrm{a}}$ & $6.8 \pm 0.3^{\mathrm{a}, \mathrm{b}}$ \\
& $286.8 \pm$ & $240.3 \pm$ & $182.3 \pm$ & $142.3 \pm$ \\
Urine $\mathrm{Na}^{+}(\mathrm{mEq} / \mathrm{l})$ & 28.2 & 34.3 & $25.2^{\mathrm{a}}$ & $22.3^{\mathrm{a}, \mathrm{b}}$ \\
& $212.4 \pm$ & $194.0 \pm 26.3$ & $153.9 \pm$ & $115.2 \pm$ \\
Urine $\mathrm{K}^{+}(\mathrm{mEq} / \mathrm{l})$ & 32.3 & & $21.3^{\mathrm{a}}$ & $18.3^{\mathrm{a}, \mathrm{b}}$ \\
& & & $175.3 \pm$ & $230.4 \pm$ \\
Serum urea (mEq/l) & $33.4 \pm 3.5$ & $68.3 \pm 3.8^{\mathrm{a}}$ & $8.8^{\mathrm{a}, \mathrm{b}}$ & $10.3^{\mathrm{a}, \mathrm{b}}$ \\
Serum creatinine & & & & \\
$(\mathrm{mEq} / \mathrm{l})$ & $1.1 \pm 0.2$ & $1.8 \pm 0.4^{\mathrm{a}}$ & $5.7 \pm 1.2^{\mathrm{a}, \mathrm{b}}$ & $7.9 \pm 1.1^{\mathrm{a}, \mathrm{b}}$ \\
Creatinine & & & $0.15 \pm$ & $0.07 \pm$ \\
clearance (mL/min) & $0.42 \pm 0.04$ & $0.3 \pm 0.03^{\mathrm{a}}$ & $0.01^{\mathrm{a}, \mathrm{b}}$ & $0.01^{\mathrm{a}, \mathrm{b}}$ \\
Microalbuminurina & & & & $78.6 \pm$ \\
$(\mathrm{mg} / \mathrm{day})$ & $0.42 \pm 0.04$ & $10.3 \pm 0.8^{\mathrm{a}}$ & $48.7 \pm 3.7^{\mathrm{a}, \mathrm{b}}$ & $4.5^{\mathrm{a}, \mathrm{b}}$ \\
\hline
\end{tabular}

a $<0.05$ compared with the control group (ANOVA followed by Student-NewmanKeuls test); ${ }^{b} \mathrm{P}<0.01$ compared with group 1 (ANOVA followed by Student-Newman-Keuls test). 
TABLE 2 - Renal function parameters of the control group and of animals with mild (group 1), moderate (group 2 and severe uremia (group 2) induced by progressive removal of renal tissue according to the technique proposed by Ormond and Miller ${ }^{11}$

Renal function parameters (at four weeks)

\begin{tabular}{ccccc} 
Parameters & Control & Group 1 & Group 2 & Group 3 \\
\hline $\begin{array}{c}\text { Serum Na } \\
(\mathrm{mEq} / \mathrm{l})\end{array}$ & $142.3 \pm 2.1$ & $146.0 \pm 2.8$ & $160.8 \pm 2.3^{\mathrm{a}}$ & $172.3 \pm 2.6^{\mathrm{a}, \mathrm{b}}$ \\
$\begin{array}{c}\text { Serum K } \\
(\mathrm{mEq} / \mathrm{l})\end{array}$ & $4.1 \pm 0.23$ & $4.6 \pm 0.5$ & $5.9 \pm 0.4^{\mathrm{a}}$ & $6.9 \pm 0.38^{\mathrm{a}, \mathrm{b}}$ \\
$\begin{array}{c}\text { Urine Na } \\
(\mathrm{mEq} / \mathrm{l})\end{array}$ & $298.8 \pm 25.2$ & $230.3 \pm 32.3$ & $172.3 \pm 22.2^{\mathrm{a}}$ & $135.3 \pm 20.3^{\mathrm{a}, \mathrm{b}}$ \\
$\begin{array}{c}\text { Urine K } \\
(\mathrm{mEq} / \mathrm{l})\end{array}$ & $222.4 \pm 32.3$ & $191.0 \pm 28.3$ & $143.9 \pm 20.3^{\mathrm{a}}$ & $108.2 \pm 17.1^{\mathrm{a}, \mathrm{b}}$ \\
$\begin{array}{c}\text { Serum urea } \\
(\mathrm{mEq} / \mathrm{l})\end{array}$ & $30.2 \pm 3.5$ & $65.3 \pm 3.9^{\mathrm{a}}$ & $185.3 \pm 8.5^{\mathrm{a}, \mathrm{b}}$ & $205.4 \pm 24.3^{\mathrm{a}, \mathrm{b}}$ \\
$\begin{array}{c}\text { Serum } \\
\text { creatinine } \\
(\mathrm{mEq} / \mathrm{l})\end{array}$ & $0.9 \pm 0.2$ & $1.7 \pm 0.48^{\mathrm{a}}$ & $6.7 \pm 1.1^{\mathrm{a}, \mathrm{b}}$ & $8.9 \pm 1.4^{\mathrm{a}, \mathrm{b}}$ \\
$\begin{array}{c}\text { Creatinine } \\
\text { clearance } \\
(\mathrm{mL} / \mathrm{min})\end{array}$ & $0.46 \pm 0.08$ & $0.3 \pm 0.05^{\mathrm{a}}$ & $0.1 \pm 0.03^{\mathrm{a}, \mathrm{b}}$ & $0.06 \pm 0.02^{\mathrm{a}, \mathrm{b}}$ \\
$\begin{array}{c}\text { Microalbu- } \\
\text { minurina } \\
(\mathrm{mg} / \mathrm{day})\end{array}$ & $5.0 \pm 0.2$ & $12.3 \pm 0.7^{\mathrm{a}}$ & $55.7 \pm 3.5^{\mathrm{a}, \mathrm{b}}$ & $85.6 \pm 4.8^{\mathrm{a}, \mathrm{b}}$ \\
\hline
\end{tabular}

aP $<0.05$ compared with the control group (ANOVA followed by Student-NewmanKeuls test); ${ }^{b}<0.01$ compared with group 1 (ANOVA followed by Student-Newman-Keuls test)

With regard to animals with moderate uremia (group 2), serum levels of urea, creatinine, $\mathrm{Na}^{+}$, and $\mathrm{K}^{+}$, as well as microalbuminuria, were significantly increased in both experimental periods $(\mathrm{p}<0.05)$. This group also presented significant decrease in urine concentrations of $\mathrm{Na}^{+}$and $\mathrm{K}^{+}$in both experimental periods $(\mathrm{p}<0.05)$. Animals of group 2 had creatinine clearance decrease of $65 \%$ after two weeks of surgery and $78 \%$ after four weeks $(p<0.05)$. The decrease in creatinine clearance of group 2 was significantly greater than in animals of the group 1 in both experimental periods $(\mathrm{p}<0.05)$.

Animals with severe uremia (group 3) presented more marked increase in serum levels of urea, creatinine, $\mathrm{Na}^{+}, \mathrm{K}^{+}$, and microalbuminuria and decreased urine concentrations of $\mathrm{Na}^{+}$and $\mathrm{K}^{+}$. All these changes reached statistically significant differences in comparison with the control group $(\mathrm{p}<0.01)$ and with groups 1 $(p<0.01)$ and $2(p<0.05)$ in both experimental periods. Animals of group 3 also had more marked decrease in creatinine clearance, both in two weeks $(84 \%, \mathrm{p}<0.01)$ and four weeks $(87 \%, \mathrm{p}<0.01)$, compared to the control group. The decrease in creatinine clearance of gropu 3 was significantly greater than in group $1(\mathrm{p}<0.01)$ and group $2(\mathrm{p}<0.05)$, in both experimental periods.

\section{Mean arterial pressure (MAP)}

As expected, animals of groups 2 and 3 presented significant increase in MAP in all measurements, in both experimental periods, compared to the control group and to group $1(p<0.05)$ (Table 3$)$. On the other hand, there was no significant difference in MAP between the groups 2 and 3 either in the twoweek or in the four-week experimental period ( $p>0.05$ ). Besides that, no significant differences were observed when comparing the MAP of each group two weeks and four weeks after surgery $(\mathrm{p}>0.05)$.

TABLE 3 - Mean arterial pressure $(\mathrm{mmHg})$ of the control group and of animals with mild (group 1), moderate (group 2 and severe uremia (group 2) induced by progressive removal of renal tissue according to the technique proposed by Ormond and Miller ${ }^{11}$

\begin{tabular}{ccccccc}
\hline \multicolumn{7}{c}{ Mean arterial pressure (mmHg) } \\
\multirow{5}{*}{ Groups } & Two weeks & \multicolumn{4}{c}{ Four weeks } \\
& 1 & 2 & 1 & 2 & 3 & 4 \\
\hline \multirow{2}{*}{ Control } & $105 \pm$ & $108 \pm$ & $107 \pm$ & $106 \pm$ & $108 \pm$ & $107 \pm$ \\
& 7.2 & 5.6 & 8.3 & 6.7 & 5.2 & 5.2 \\
Group 1 & $110 \pm$ & $112 \pm$ & $112 \pm$ & $114 \pm$ & $112 \pm$ & $116 \pm$ \\
& 7.5 & 7.3 & 6.7 & 8.2 & 7.8 & 7.5 \\
Group 2 & $155 \pm$ & $160 \pm$ & $157 \pm$ & $160 \pm$ & $158 \pm$ & $161 \pm$ \\
& $4.3^{\mathrm{a}, \mathrm{b}}$ & $5.8^{\mathrm{a}, \mathrm{b}}$ & $6.3^{\mathrm{a}, \mathrm{b}}$ & $4.1^{\mathrm{a}, \mathrm{b}}$ & $6.8^{\mathrm{a}, \mathrm{b}}$ & $8.2^{\mathrm{a}, \mathrm{b}}$ \\
Group 3 & $163 \pm$ & $165 \pm$ & $160 \pm$ & $165 \pm$ & $162 \pm$ & $165 \pm$ \\
& $5.3^{\mathrm{a}, \mathrm{b}}$ & $5.8^{\mathrm{a}, \mathrm{b}}$ & $6.3^{\mathrm{a}, \mathrm{b}}$ & $6.3^{\mathrm{a}, \mathrm{b}}$ & $6.2^{\mathrm{a}, \mathrm{b}}$ & $6.7^{\mathrm{a}, \mathrm{b}}$ \\
\hline
\end{tabular}

${ }^{a} \mathrm{P}<0.05$ compared with the control group (ANOVA followed by Student-NewmanKeuls test); ${ }^{\mathrm{P}}<0.01$ compared with group 1 (ANOVA followed by Student-Newman-Keuls test).

\section{Histopathological analysis}

Renal morphology of the different experimental groups, two and four weeks after surgery, is shown, respectively, in Figures 4 and 5 (A, B, C and D). Histopathological analysis of the renal tissue of animals with mild uremia, both two weeks (Figure 4B) and four weeks (Figure 5B) after surgery, showed small differences in comparison to the control group (Figures 4A and 5A), being observable only increased mesangial cellularity, hyperemia and mild glomerular hypetrophy. However, animals with moderate uremia (Figures 4C and 5C) and with severe uremia (Figures 4D and 5D) presented dilated and hypotrophic tubules with the presence of hyaline material, with aspect of pseudothyroidization. The histopathological changes, despite being similar in groups 2 
and 3, were more marked in group 3, both at two weeks and four weeks after surgery.
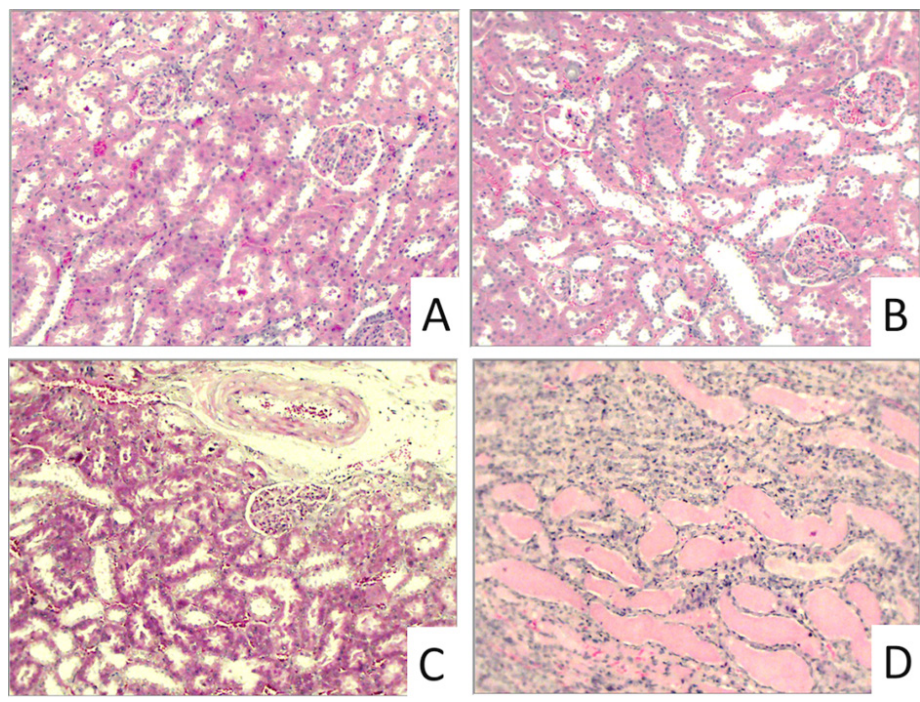

FIGURE 4 - Representative micrographs of renal tissue, stained with Hematoxilin-Eosin of the experimental groups two weeks after surgical procedure (x400): A. Renal tissue of control group (sham-operated animals), with normal renal morphology; $\mathbf{B}$. Renal tissue of animals with mild uremia (group 1) exhibiting an increase of mesangial cellularity and mild glomerular hyperthrophy; $\mathbf{C}$. Renal tissue of animals with moderate uremia (group 2) presenting dilated and hypotrophic tubules with hyaline material in the lumen, and having an aspect of pseudothyroidization; D. Renal tissue of animals with severe uremia (group 3) showing accentuated tubular hypothrophy, interstitial fibrosis and more intense pseudothyroidization.
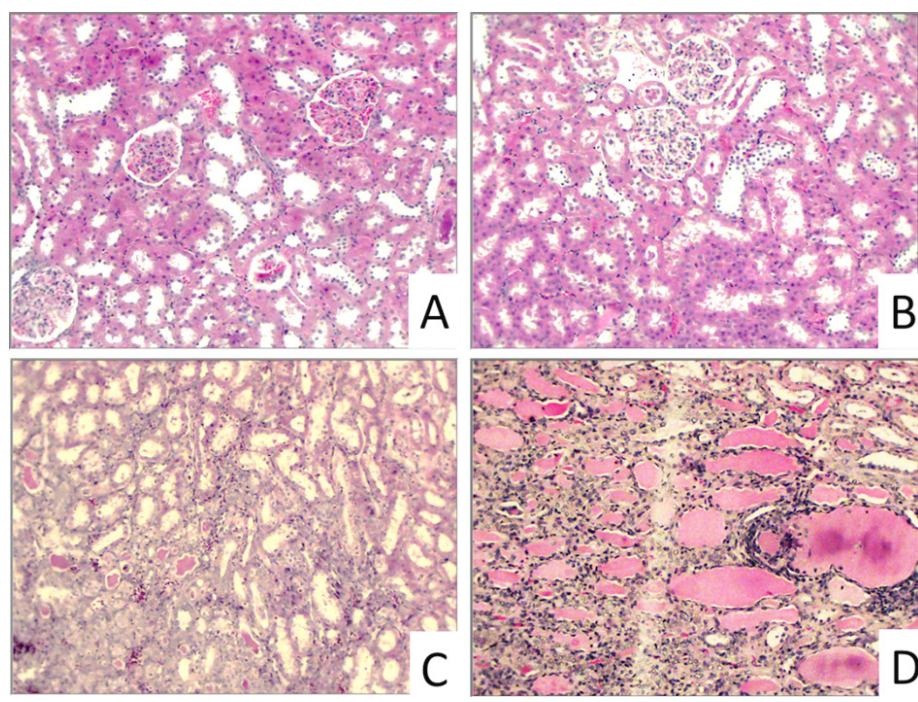

FIGURE 5 - Representative micrographs of renal tissue, stained with Hematoxilin-Eosin of the experimental groups four weeks after surgical procedure (x400): A. Renal tissue of control group (sham-operated animals), with normal renal morphology; $\mathbf{B}$. Renal tissue of animals with mild uremia (group 1) exhibiting an increase of mesangial cellularity and mild glomerular hyperthrophy; C. Renal tissue of animals with moderate uremia (group 2) presenting dilated and hypotrophic tubules with hyaline material in the lumen, and having an aspect of pseudothyroidization; D. Renal tissue of animals with severe uremia (group 3) showing accentuated tubular hypothrophy, interstitial fibrosis and more intense pseudothyroidization.

\section{Discussion}

The development of accurate experimental models for the study of CKD remains a challenge ${ }^{16}$. These models are based on the use of chemical substances ${ }^{8-10}$ or surgical produres that considerably reduce the renal tissue mass ${ }^{11-16}$. The pharmacologic models consist on the use of substance with nephrotoxic potential, which produce injuries to the renal tissue through different molecular mechanisms ${ }^{8-10}$. These models have the disadvantage that it is not always possible to establish the exact dose to produce a specific degree of renal insufficiency, in addition to the possible occurrence of side effects that may compromise the experimental model. On the other hand, the surgical procedures, characterized by the removal of portions of the renal tissue, have been widely used because they have a high survival rate and a low cost, do not have side effects and can be used to produce progressive levels of renal failure, as shown in this study ${ }^{11-16}$.

In the present study, three distinct degrees of CKD were obtained: mild, moderate, and severe, induced by progressive removal of renal tissue based on the technique originally described by Ormrod and Miller ${ }^{11}$. As expected, we have obtained three different degrees of $\mathrm{CKD}$, with changes in renal function parameters similar to those obtained by Ormrod and Miller ${ }^{11}$. Those authors classified the degrees of CKD based on serum levels of urea, being 40 to $80 \mathrm{mg} / \mathrm{dL}$ considered mild CKD, 100 to $200 \mathrm{mg} / \mathrm{dL}$ considered moderate CKD, and $200 \mathrm{mg} / \mathrm{dL}$ or higher considered severe CKD. ${ }^{11}$ These results were similar to those observed in the present study in the three degrees of CKD and in both experimental periods. Similarly, other studies showed an increase of $50 \%$ in serum urea of rats submitted to $5 / 6$ nephrectomy, which was associated to an increase of $50 \%$ in serum creatinine. In our study, the group of severe uremia (group 3) resulted in an increase of $85 \%$ in serum urea and a $90 \%$ increase in serum creatinine. The discrepancy of these results could be explained by the use of differente species and/or lineages of animals and due to differences in surgical protocols of renal tissue removal ${ }^{11-14}$.

As expected, the three degrees of CKD resulted in progressive loss of glomerular filtration rate (GFR) estimated by creatinine clearance. Even though creatinine clearance is less accurate in rats than it is in other species, as dogs, for example, to estimate GFR, many classical studies have shown that creatinine clearance has a good correlation with inulin clearance in Wistar rats, especially when assessed in comparative terms, as in our study ${ }^{17,18}$. These data are in accordance with those of Ormrod e Miller ${ }^{11}$ about the percentage of reduction in creatinine clearance of animals with CKD, compared to the control group. However, our estimation 
of GFR, obtained by measurement of creatinine clearance of the experimental groups, resulted in values significantly lower than those obtained by Ormrod and Miller, who used Dark Agouti rats and evaluated GFR using the ${ }^{51} \mathrm{Cr}$-EDTA clearance method ${ }^{11}$. This difference in GFR estimation can be explained, at least in part, by the use of different stains of rats and different methods for GFR estimation. It is worth mentioning that in some strains of rats tubular reabsorption of endogenous creatinine can occur in varying degrees ${ }^{19}$. It has been demonstrated that about $30-50 \%$ of filtered creatinine is reabsorbed in Fisher rats ${ }^{20}$, and about $45 \%$ in diabetic rats ${ }^{17}$.

Previous studies have shown a decrease of about $50 \%$ in creatinine clearance in rats and mice four weeks after 5/6 nephrectomy ${ }^{12,13,21}$. Under our experimental conditions, the creatinine clearance reduction in the group of severe uremia was of $87 \%$. This value is consistent with the degree of renal insufficiency we intended to induce. Therefore, the group of severe uremia corresponds to ESRD, as it results in a degree of CKD similar to that observed in patients that required renal replacement therapy ${ }^{22}$.

On the other hand, despite the significant decrease in GFR, a significant and apparently paradoxical increase in urine output and water intake was observed in the animals of groups 2 and 3 , in both experimental periods. Similarly, Skott et al. ${ }^{23}$ showed a significant increase in urine output and water intake in rats submitted to $5 / 6$ nephrectomy two weeks after surgery. It is possible to hypothesize that the polyuria and the resulting polydipsia observed in our study can be attributed to alterations in the mechanisms of urine concentation related, at least in part, to the inability of vasopressin to stimulate the reabsorption of water in the collecting duct, as observed in patients with advanced $\mathrm{CKD}$, that presented hypotonic urine in relation to plasma, even after administration of supramaximal doses of vasopressin ${ }^{24,25}$. Accordingly, Kwon et al. ${ }^{26}$ showed that rats submitted to 5/6 nephrectomy presented significant decrease in renal expression of the genes of the aquaporins 1 (AQP1), 2 (AQP2) and 3 (AQP3), with resulting polyuria and polydipsia. These authors also observed that chronic treatment with the arginine vasopressin analogue DDAVP was not able to reverse the decrease in the expression of the genes AQP1, AQP2 and AQP3 and the consequent polyuria of the animals with $\mathrm{CKD}^{26}$. Also, it is well-kwown that rats with CKD induced by $5 / 6$ nephrectomy have increased plasma levels of vasopressin ${ }^{27}$. These data suggest that the elevated vasopressin concentrations can lead to down-regulation of AQP2 expression in the collecting duct of animals with $\mathrm{CKD}^{26}$.
In addition to polyuria and polydipsia, animals with moderate (group 2) and with severe uremia (group 3) presented reduced urine concentrations of $\mathrm{Na}^{+} \mathrm{e}^{+}$and increased serum levels of these ions. Similar results were obtained by Skott et $a l .{ }^{23}$ and Kwon et $a .^{26}$. These data reinforce the hypothesis of peripheral resistance to vasopressin, whose plasma levels would be elevated in response to the increased serum osmolarity caused by the increased serum $\mathrm{Na}^{+}$levels observed in groups 2 and $3 .{ }^{27}$ Peripheral resistance to vasopressin prevents reabsorption of water and, as consequence, urine concentrations of $\mathrm{Na}^{+}$and $\mathrm{K}^{+}$ are decreased. Additionaly, down-regulation of AQP2 and AQP3 may occur ${ }^{26}$, what could contribute even more for the alterations of the urine-concentrating mechanisms observed in the CKD. Polyuria and polydipsia with alteration of the mechanisms of urine concentration have also been reported in other experimental models that lead to marked renal failure, as in the case of hepatorenal syndrome induced by common bile duct ligation in rats $^{28}$.

Another alteration found under our experimental conditions was microalbuminuria. Especially in group 3, we observed pronounced microalbuminuria both two weeks and four weeks after surgery, as previous studies have also shown ${ }^{12,13,21,23}$. However, animals of groups 2 and 3 also presented significant microalbuminuria in comparison to the control group. It is known that increased urinary excretion of albumin is a reliable marker of CKD severity and is an independent predictor of its progression ${ }^{7}$. Microalbuminuria reflects alterations of glomerular filtration characterized by loss of selective permeability and triggers an immune-inflammatory and fibrogenic response that leads to progressive glomerular injury ${ }^{7}$.

With regard to MAP, we observed significant increase in animals with moderate and severe uremia. Similar results were obtained by other authors using rats submitted to $5 / 6$ nephrectomy ${ }^{11-14,21,23}$. The main mechanism of hypertension in CKD is related to the progressive loss of renal ability to excrete sodium, resulting in sodium and volume overload. Furthermore, other mechanisms can also be involved. For example, endothelial dysfunction caused by hypertension can lead to increased production of vasoconstrictor substances such as angiotensin II and decreased levels of vasodilator mediators such as nitric oxide and prostacyclin ${ }^{29,30}$.

Renal histological analysis showed, as expected, histological patterns compatible with ESRD in group $3^{11,13,21}$. In the same way, rats of group 2 presented the same changes found in group 3, although with lower intensity, compatible with moderate CKD (stages 3 or 4 ). On the other hand, animals with mild uremia 
did not have significant morphological and structural changes, being observable only increased mesangial cellularity, hyperemia and mild glomerular hypetrophy. Therefore, the functional alterations observed in group 1 were not accompanied by important changes in renal histology. These characteristics are compatible with initial stages of $\mathrm{CKD}^{5}$. Physiopathology of CKD is initially associated with hypetrophy of remnant nephrons in response to loss of renal mass. As consequence, the nephrons suffer changes in glomerular surface and in basement membrane permeability to proteins ${ }^{4}$. These glomerular alterations lead to renal production of growth factors, cytokines, chemokines, and to the activation of the renin-angiotensin system ${ }^{1}$. These substances are involved in the process of renal cellular proliferation, intraglomerular coagulation, recruitment and proliferation of immune cells, increase in cellular matrix, collagen proliferation, and fibrosis ${ }^{5}$

We are aware of the limitations of our study. The main weakness of our study was the absence of an investigation about the mechanisms beyond renal dysfunction and kidney tissue structural changes. For instance, renal tissue measurement of collagen deposition and of inflammatory markers will be of interest to decifer the molecular mechanisms of progressive renal damage. Further studies are necessary to evaluate molecular pathways related to renal changes in this experimental model.

To summarize, the present study showed that the induction of severe uremia by surgical removal of great portions of renal tissue ${ }^{11}$ produces ESRD in rats characterized by classical changes in the parameters of renal function, including increased serum creatinine, urea, $\mathrm{Na}^{+}$, and $\mathrm{K}^{+}$, increased microalbuminuria, decreased creatinine clearance, besides inducing polyuria, polydipsia, decreased urine concentrations of $\mathrm{Na}^{+}$and $\mathrm{K}^{+}$and arterial hypertension. It was also shown that changes in the parameters of renal function and blood pressure levels observed two weeks after surgery did not present significant differences from those observed at four weeks after surgery. Moderate uremia ${ }^{11}$ characterized CKD stages 3 to 4, with significant functional and morphological changes, but not so severe as in group 3. On the other hand, the induction of mild uremia ${ }^{11}$ was compatible with CKD stages 1 to 2, with mild functional and structural changes.

\section{Conclusion}

The experimental model of progressive degrees of nephrectomy leading to mild, moderate and severe uremia seems to be useful to study CKD physiopathology, its mechanisms of progression and to evaluate potential pharmacological targets for the treatment of CKD.

\section{References}

1. Vianna HR, Soares CM, Tavares MS, Teixeira MM, Simões e Silva AC. Inflammation in chronic kidney disease: the role of cytokines. J Bras Nefrol. 2011 Jul-Sep;33(3):351-64. PMID: 22042353.

2. Stenvinkel P. Chronic kidney disease: a public health priority and harbinger of premature cardiovascular disease. J Intern Med. 2010 Nov;268(5):456-67. PMID: 20809922.

3. Meguid El Nahas A, Bello AK. Chronic kidney disease: the global challenge. Lancet. 2005 Jan 22-28;365(9456):331-40. PMID: 15664230 .

4. Atkins RC. The epidemiology of chronic kidney disease. Kidney Int Suppl. 2005 Apr;(94):S14-8. PMID: 15752232.

5. Zimmermann J, Herrlinger S, Pruy A, Metzger T, Wanner C. Inflammation enhances cardiovascular risk and mortality in hemodialysis patients. Kidney Int. 1999 Feb;55(2):648-58. PMID: 9987089.

6. Stenvinkel P, Carrero JJ, Axelsson J, Lindholm B, Heimbürger O, Massy Z. Emerging biomarkers for evaluating cardiovascular risk in the chronic kidney disease patient: how do new pieces fit into the uremic puzzle? Clin J Am Soc Nephrol. 2008 Mar;3(2):505-21. PMID: 18184879.

7. lsaza C, de Seigneux S, Martin PY. Proteinuria: pathophysiology and clinical implications. Rev Med Suisse. 2012 Feb 29;8(330):46672. PMID: 22452133.

8. Piao SG, Bae SK, Lim SW, Song JH, Chung BH, Choi BS, Yang $\mathrm{CW}$. Drug interaction between cyclosporine and mTOR inhibitors in experimental model of chronic cyclosporine nephrotoxicity and pancreatic islet dysfunction. Transplantation. 2012 Feb 27;93(4):383-9. PMID: 22267156.

9. Zhao YY, Liu J, Cheng XL, Bai X, Lin RC. Urinary metabonomics study on biochemical changes in an experimental model of chronic renal failure by adenine based on UPLC Q-TOF/MS. Clin Chim Acta. 2012 Mar 22;413(5-6):642-9. PMID: 22227165.

10. Lu Z, Xie Y, Liu X, Cui S, Wu Y, Cai C, Zhang L, Chen X. Effect of 5/6 nephrectomized rat serum on epithelial-to-mesenchymal transition in vitro. Ren Fail. 2011;33(6):600-8. PMID: 21663389.

11. Ormrod D, Miller T. Experimental uremia. Description of a model producing varying degrees of stable uremia. Nephron. 1980;26(5):249-54. PMID: 7422053.

12. Jia Z, Wang H, Yang T. Microsomal prostaglandin E synthase 1 deletion retards renal disease progression but exacerbates anemia in mice with renal mass reduction. Hypertension. 2012 Jan;59(1):1228. PMID: 22106404.

13. Sun L, Zhang D, Liu F, Xiang X, Ling G, Xiao L, Liu Y, Zhu X, Zhan M, Yang Y, Kondeti VK, Kanwar YS. Low-dose paclitaxel ameliorates fibrosis in the remnant kidney model by down-regulating miR-192. J Pathol. 2011 Nov;225(3):364-77. PMID: 21984124.

14. Fukuda A, Wickman LT, Venkatareddy MP, Sato Y, Chowdhury MA, Wang SQ, Shedden KA, Dysko RC, Wiggins JE, Wiggins RC. Angiotensin II-dependent persistent podocyte loss from destabilized glomeruli causes progression of end stage kidney disease. Kidney Int. 2012 Jan;81(1):40-55. PMID: 21937979.

15. Pohjolainen V, Rysä J, Näpänkangas J, Kööbi P, Eräranta A, Ilves M, Serpi R, Pörsti I, Ruskoaho H. Left ventricular periostin gene expression is associated with fibrogenesis in experimental renal insufficiency. Nephrol Dial Transplant. 2012 Jan;27(1):115-22. PMID: 21712488.

16. Eddy AA, López-Guisa JM, Okamura DM, Yamaguchi I. Investigating mechanisms of chronic kidney disease in mouse models. Pediatr Nephrol. 2012 Aug;27(8):1233-47. PMID: 21695449.

17. Van Liew JB, Zamlauski-Tucker MJ, Feld LG. Endogenous creatinine 
clearance in the rat: strain variation. Life Sci. 1993;53(12):1015-21. PMID: 8361325.

18. Tanaka R, Kon V, Yoshioka T, Ichikawa I, Fogo A. Angiotensin converting enzyme inhibitor modulates glomerular function and structure by distinct mechanisms. Kidney Int. 1994 Feb;45(2):53743. PMID: 8164442.

19. Bankir L, Kriz W. Adaptation of the kidney to protein intake and to urine concentrating activity: similar consequences in health and CRF. Kidney Int. 1995 Jan;47(1):7-24. PMID: 7731172.

20. Namnum P, Insogna K, Baggish D, Hayslett JP. Evidence for bidirectional net movement of creatinine in the rat kidney. Am J Physiol. 1983 Jun;244(6):F719-23. PMID: 6859263.

21. Fujihara CK, Malheiros DM, Zatz R. Losartan-hydrochlorothiazide association promotes lasting blood pressure normalization and completely arrests long-term renal injury in the 5/6 ablation model. Am J Physiol Renal Physiol. 2007 Jun;292(6):F1810-8. PMID: 17344184 .

22. Cooper BA, Branley P, Bulfone L, Collins JF, Craig JC, Fraenkel MB, Harris A, Johnson DW, Kesselhut J, Li JJ, Luxton G, Pilmore A, Tiller DJ, Harris DC, Pollock CA. A randomized, controlled trial of early versus late initiation of dialysis. N Engl J Med. 2010 Aug 12;363(7):609-19. PMID: 20581422.

23. Skott M, Nørregaard R, Sorensen HB, Kwon TH, Frøkiaer J, Nielsen $\mathrm{S}$. Pre-existing renal failure worsens the outcome after intestinal ischaemia and reperfusion in rats. Nephrol Dial Transplant. 2010 Nov;25(11):3509-17 PMID: 20525977.

24. Wilson DR, Sonnenberg H. Medullary collecting duct function in the remnant kidney before and after volume expansion. Kidney Int. 1979 May;15(5):487-501. PMID: 480782.

25. Tannen RL, Regal EM, Dunn MJ, Schrier RW. Vasopressin-resistant hyposthenuria in advanced chronic renal disease. $\mathrm{N}$ Engl $\mathrm{J}$ Med. 1969 May 22;280(21):1135-41. PMID: 5782121.

26. Kwon TH, Frøkiaer J, Knepper MA, Nielsen S. Reduced AQP1, -2 , and -3 levels in kidneys of rats with CRF induced by surgical reduction in renal mass. Am J Physiol. 1998 Nov;275(5 Pt 2):F72441. PMID: 9815130.

27. Bouby N, Bachmann S, Bichet D, Bankir L. Effect of water intake on the progression of chronic renal failure in the $5 / 6$ nephrectomized rat. Am J Physiol. 1990 Apr;258(4 Pt 2):F973-9. PMID: 2184677.

28. Pereira RM, dos Santos RA, Oliveira EA, Leite VH, Dias FL, Rezende AS, Costa LP, Barcelos LS, Teixeira MM, Simões e Silva AC. Development of hepatorenal syndrome in bile duct ligated rats. World J Gastroenterol. 2008 Jul 28;14(28):4505-11. PMID: 18680230 .
29. Go AS, Chertow GM, Fan D, McCulloch CE, Hsu CY. Chronic kidney disease and the risks of death, cardiovascular events, and hospitalization. N Engl J Med. 2004 Sep 23;351(13):1296-305. PMID: 15385656.

30. Ghosh SS, Krieg R, Massey HD, Sica DA, Fakhry I, Ghosh S, Gehr TW. Curcumin and enalapril ameliorate renal failure by antagonizing inflammation in 5/6 nephrectomized rats: role of phospholipase and cyclooxygenase. Am J Physiol Renal Physiol. 2012 Feb 15;302(4):F439-54. PMID: 22031851.

\section{Acknowledgements}

To all members of the Interdisciplinary Laboratory of Medical Investigation, Faculty of Medicine, Federal University of Minas Gerais, and Faculty of Medicine of Itajubá-MG for technical support.

\section{Correspondence:}

Ana Cristina Simões e Silva

Laboratório Interdisciplinar de Investigação Médica

Faculdade de Medicina, UFMG

Avenida Alfredo Balena, 190/281

30130-100 Belo Horizonte - MG Brasil

Tel.: (55 31)3409-8073

Fax: (55 31)3409-9770

acssilva@hotmail.com

ana@medicina.ufmg.br

Received: July 19, 2016

Review: Sep 20, 2016

Accepted: Oct 18, 2016

Conflict of interest: none

Financial sources: FAPEMIG (PPM 00555-15), CNPq (Processes numbers 470472/2014-6 and 460334/2014-0), and CAPES.

${ }^{1}$ Research performed at School of Medicine of Itajubá-MG, Brazil. 